\title{
A LINGUAGEM ESCRITA E A APRENDIZAGEM NA ACADEMIA
}

\author{
Angela Alenice Rothmund ${ }^{1}$ \\ Felipe Gustsack ${ }^{2}$ \\ Simone Wilgen ${ }^{3}$
}

\section{RESUMO}

Viemos, através deste artigo, trazer reflexões sobre um projeto do qual somos bolsistas e que visa investigar as dificuldades enfrentadas pelos professores quanto à linguagem escrita, tanto na produção de textos durante sua formação, quanto nas propostas que apresentam aos alunos como metodologia para práticas de escrita e textualização. O estudo envolveu alunas/os de Cursos de Pedagogia presencial, da UNISC, e a distância, da UFRGS, do Mestrado em Educação - UNISC, bem como seis crianças, pais e professores da Escola Municipal de Ensino Fundamental Elemar Guilherme Kroth de Vera Cruz - RS, discutindo as práticas pedagógicas para o trabalho com a escrita na vivência escolar. Estudamos a linguagem escrita de professores a partir de uma abordagem complexa, articulando princípios da pesquisa participante e da Análise do Discurso com ações de pesquisa-ação, pois a aprendizagem na educação está diretamente relacionada com a qualidade da comunicação que se estabelece entre os que vivenciam o processo educativo, e isto implica o uso adequado da linguagem, especialmente da escrita, quando trabalhamos com diversas tecnologias. Somos seres que habitamos na linguagem, portanto, partimos da ideia de que nós humanos nos estruturamos como sistemas autopoiéticos, desenvolvendo as características biológicas e o domínio de saberes e valores que nos permitem produzirmos a nós mesmos. Conclusões apontam a carência de práticas de escrita prazerosa na academia como causadora de insuficiências em nossas aprendizagens.

Palavras-chave: Linguagens. Escrita. Professores. Autopoiese. Análise do discurso.

\section{ABSTRACT}

We came through this article, to bring reflections on a project which aimed at scholars and we are investigating the difficulties faced by teachers and written language, both in the production of texts during their training, and the proposals they presented to students as practice methodology for writing and textualization. The study involved students in Pedagogy Course education in attendance at UNISC, and distance education at UFRGS, the Master of Education - UNISC and six children, parents and teachers in the School Hall Elementary School William Elemar Kroth in the city of Vera

1 Discente de Psicologia. E-mail: aarothmund@unisc.br - PPGEDU/Mestrado em Educação - Bolsista Fapergs.

2 Doutor em Educação. E-mail: fegus@unisc.br - PPGEDU/Mestrado em Educação - Professor e Coordenador.

3 Discente de Psicologia. E-mail: simonewilgen@mx2.unisc.br - PPGEDU/Mestrado em Educação Bolsista CNPq. 
Cruz - RS discussing the pedagogical practices for working with the writing on the school experience. We study the written language teachers from a complex approach, combining the principles of participatory research and discourse analysis shares with action research, because learning in education is directly related to the quality of communication that established between those who experience the educational process, and this implies the proper use of language, especially writing, when working with various technologies. We are beings who inhabit the language, therefore, we set the idea that us, humans we are beings structured as autopoietic systems, and developing the biological domain knowledge and values that enable us to produce ourselves. Conclusions point to the lack of writing practice in the gym enjoyable as the cause of shortcomings in our learning.

Keywords: Languages. Writing Teachers. Autopoiesis. Discourse Analysis.

\section{APRESENTAÇÃO}

As reflexões que apresentamos emergem das atividades que realizamos como bolsistas de iniciação científica junto ao Projeto de Pesquisa: Educação e Linguagens: a escrita e os professores, coordenado pelo Professor Felipe Gustsack. Com este projeto investigamos as práticas de escrita de professores em formação dos cursos de pedagogia da UNISC (presencial) e da UFRGS (ead). Do ponto de vista teórico trabalhamos com o conceito de autopoiese (MATURANA; VARELA, 1997). Ou seja, partimos do pressuposto de que somos seres que habitamos na linguagem, enfatizando a idéia de que nós humanos nos estruturamos como sistemas autopoiéticos, desenvolvendo as características biológicas e o domínio de saberes e valores que nos permitem produzirmos a nós mesmos. Além disso, defendemos a idéia de que a qualidade da educação está diretamente relacionada com a qualidade da comunicação que se estabelece entre aqueles que vivenciam o processo educativo, e que este, necessariamente implica um domínio adequado da linguagem, especialmente da escrita. Afinal, ainda que a comunicação não seja a única função da linguagem, mas sim uma das suas mais importantes possibilidades, a aprendizagem é um fenômeno biológico e comunicacional. Isso quer dizer que a sobrevivência é uma questão de acoplamento com a realidade e para isso a linguagem é um fator fundamental. Em outras palavras: "Na medida em que os seres humanos são sistemas autopoiéticos, todas as suas atividades como organismos sociais devem satisfazer sua autopoiesis." (MATURANA; VARELA, 1980, p. XXVI).

Os seres humanos se constroem na linguagem tanto na sua dimensão ontogênica como cognitiva. Portanto, o processo autopoiético (auto-construção) se dá através de um processo de linguajar - emocionar.

O conhecer é mais do que somente uma função cognitiva, uma vez que os processos de aprendizagem social se apresentam nas interações comportamentais dos seres vivos, e são construídos nesse viés de atravessamentos históricos, sociais, culturais, econômicos, religiosos e ambientais. Assim, desacreditamos da ideia evolucionista em que na carga genética, através do processo de seleção evolutiva, simplesmente a espécie armazenou informações de sobrevivência. Essa falsa ideia de uma realidade pré-existente, conforme o conhecimento tradicional, não se aplica ao 
pensar o ser humano habitando na linguagem, pois conhecer não se resume à evolução biológica, ou internalizar algo previamente construído na sociedade. Ao contrário, o conhecer ocorre no ser. Assim, por exemplo, cada pessoa, dependendo de sua história, compreenderá de diferentes maneiras as modificações da maré, e essa compreensão, mesmo sendo passada adiante, se dará somente como concepção intelectual, informacional deste ser que a recebe, podendo tornar-se uma compreensão, uma aprendizagem, na medida em que também este possa observar a maré, confirmando os sentidos da informação anteriormente recebida. Daí que toda a aprendizagem tenha a ver com 'experiência', não se configurando apenas a partir de informações e/ou observações externas de um fenômeno.

"Viver é conhecer - conhecer é viver" (MATURANA E VARELA, 1991, p. 116). Nesse sentido, viver é sempre ação efetiva que implica em construção de conhecimento-realidade-sujeito. Essa experiência sempre nos transforma, pois se dá em nível anatômico, fisiológico, cognitivo e emocional devido à plasticidade de nosso sistema nervoso e psíquico. Ainda conforme os autores, a dimensão rede do funcionamento dos vivos nos mostra o papel das conexões no desenvolvimento dos seres vivos. $\mathrm{O}$ modelo da vida é o modelo de redes presentes não somente no nível relacional com o mundo externo, mas também internamente com as redes de conexões orgânicas.

Assim, criar conhecimento tem a ver com a peculiaridade de construir esse mundo e os seus sentidos, e isso significa que atuamos na linguagem, a qual "é nossa maneira particular de ser humano e estar no fazer humano" (MATURANA e VARELA, 2001 p. 32). Ao agir na linguagem, que é um fenômeno social, construído pelos homens, que dá suporte às coordenações de conduta em que nos modificamos para conservarmos nossa existência em determinado meio, estamos constituindo a nós mesmos enquanto construímos o mundo em um constante vir a ser. No centro dessa explicação, que é a Teoria da Biologia da Cognição, está o conceito de Autopoiesis de Maturana e Varela que, como todos os outros aspectos que estamos descrevendo aqui, também é complexo na medida em que expressa que os seres vivos são sistemas fechados à informação e, ao mesmo tempo, abertos à troca de energia. Sermos fechados para a informação significa que somos auto-produtores de nós mesmos, na medida em que o que vem de fora apenas perturba e dispara mobilizações internas, mas não determina o que nos acontece. Assim, uma informação pode continuar sendo apenas informação, ou transformar-se em conhecimento.

Por outro lado, os seres vivos são sistemas abertos às trocas de energia com o que lhes é externo o que os mantém em reorganização constante e reversão de entropia. Sendo assim, podemos dizer que conhecer é um processo autopoiético, em que poien em grego, significa produzir, criar. Autopoiese significa autocriar ou auto produzir. Todo ser vivo caracteriza-se literalmente, por produzir continuamente a si próprio, como organismo vivo, que interage com todos os organismos vivos, e se constrói nesses atravessamentos, em que viver é modificar-se, movimentar-se, aprender, como um permanente devir.

Partindo dessas compreensões, em oficinas com professoras em formação refletimos acerca das características da escrita não apenas como prática necessária à formação docente e constitutiva do processo avaliativo na academia, mas também a sua relevância para a formação humana, que se traduz como um modo específico de aprender a pensar. Ou seja, acreditamos que o que aprendemos, e como aprendemos 
nas práticas da escrita, só é possível através dessas mesmas práticas de escrita. Explicando melhor, ser um bom leitor não faz de alguém um bom escritor. É na experiência do escrever, em que dominar a escrita é uma aprendizagem ímpar de outras aprendizagens, que se dá em um constante aprimoramento de autoproduzir-se como escritor. De modo algum, pretendemos desmerecer as outras formas de linguagem, mas sim, apontar para o entendimento de que as diversas linguagens são modos diversos de nos colocarmos em nosso constante devir. Afinal, são múltiplas e ímpares, cada qual nos permitindo diferentes saberes e diferentes meios de construir nosso mundo.

Em torno desse tema das diferenças, vale lembrar que, Richard Sennett (2009, p. 182) traz uma discussão sobre o trabalho cooperativo, fazendo um viés interpretativo sobre os dedos da mão e a cooperatividade. Pela falta de assimetria dos dedos da mão, que tem comprimentos e flexibilidades diferentes, as quais impedem a perfeita coordenação, inclusive nos polegares, e ainda as diferenças de ser a pessoa destra ou canhota, a cooperação só e possível porque ocorre uma série de compensações por parte de cada um dos dedos, o que nos leva a concluir acerca da cooperação entre diferentes, já que entre iguais ela não é tão necessária. As habilidades manuais são atingidas de modo elevado, contudo, essas desigualdades entre os dedos, são compensadas pelas próprias diferenças, em que polegares executam ações que outros dedos não são capazes. O que Sennett nós traz, possibilita uma interpretação menos abstrata das diferentes formas de se apropriar de diversos conhecimentos, da pluralidade das formas como nos conhecemos, das diversas linguagens que possibilitam construir e criar o mundo e os modos de ver este mundo. Ou seja, as diferentes linguagens possuem esse quê de compensatório e diversificado, afinal, cada linguagem, seja o escrever, o falar, o ler, o desenhar, o cantar, o ouvir, representa diversos meios de se habitar nesse mundo e cada um coopera com o outro.

Atualmente nos envolvemos com a realização de análises de textos produzidos pelas professoras em processos avaliativos para as quais nos utilizamos da metodologia da análise do discurso segundo as contribuições de Michel Pêcheux (1999), Helena Brandão (2004) e Eni Orlandi (1996). Partimos do princípio da linguagem como fato social, ideia introduzida pelos estudos de Saussurre, que foram retomados por Brandão (1996) e que muitos outros teóricos se propuseram a estudar no desenvolvimento da sociedade, em que a existência da língua foi fundada a partir das necessidades de comunicação das pessoas. A visão da linguagem como interação social mostra que nem o ouvinte, ou o orador são sujeitos passivos na constituição dos significados de uma enunciação, demonstrando que há relações intrínsecas entre linguagens, contexto social e o outro. Este outro desempenha papel fundamental na construção dos significados, uma vez que elabora o conteúdo segundo suas condições e a orientação social. Isto é, busca se adaptar ao seu meio, no intuito de interagir nas relações sociais, que dão o formato para o comportamento da pessoa, através, e nas linguagens. Nas palavras de Brandão, é "o percurso que o individuo faz da elaboração mental do conteúdo, a ser expresso à objetivação externa" (1996, p. 10). Nessa perspectiva, pois, a linguística não dá conta do estudo intrínseco da linguagem, sendo isso que nos leva à análise do discurso.

Pensamos ser necessário trazer para o cerne das discussões acerca das linguagens uma compreensão que "articule o linguístico e o social" (BRANDÃO, 1996, p. 10), pois, "a linguagem é um distanciamento entre a coisa representada e o signo 
que a representa. E é nessa distancia, no interstício entre a coisa e sua representação que reside o ideológico". A partir deste pressuposto buscam-se as relações da ideologia na linguagem. A palavra como produto da interação social, é um signo ideológico, que pode retratar as diferentes formas de significar a realidade, e pela sua pluralidade, mostra-se como campo frutífero para as manifestações ideológicas. A linguagem perde seu caráter abstrato, aparecendo como o lugar "em que a ideologia se manifesta concretamente" (BRANDÃO, 1996, p. 11), pois, o signo ideológico não é somente uma manifestação, ou reflexo da realidade, mas sim um fragmento material. Sendo assim, a realidade do signo é objetiva, tornando-se objeto de estudo metodológico e objetivo. Mas, vale lembrar, ainda, que o caráter ideológico vai além do signo, sendo visível nas formas. Nas palavras de Bakhtin (1979), citado por Brandão (1996, p. 11), "no funcionamento significante da linguagem que é o lugar onde se dá a sua materialidade".

A partir de então, estudiosos passam a pesquisar uma compreensão que vai além do fenômeno da linguagem centrado na língua, ou como sistema neutro de ideologias. Pelo contrário, passam a compreender a linguagem como local onde se materializam as ideologias predominantes, e é nessa instância da linguagem que o discurso toma forma. Os estudos do discurso permitem operar as ligações necessárias entre o que é linguística e as condições extralinguísticas, em que as condições e atravessamentos sócio-históricos que compõem o texto têm papel principal e constitutivo de cada significação. Aí, na compreensão de Haroche (1971), referido por Brandão (1996), está o campo do discurso, que é o ponto de articulação entre os processos ideológicos e os fenômenos linguísticos sociais.

A linguagem enquanto discurso não é somente uma forma de interação social, mas sim um modo de produção social dos sujeitos, não sendo neutra ou inocente, na medida em que está engajada em uma intencionalidade ideológica de algum sistema, e não é algo natural, que se possa dizer inato ao ser vivo, mas local em que a ideologia tem seu campo de expansão. Aparecendo, conforme Braga (1980), citado por Brandão (1996), como "sistema suporte das representações ideológicas (...) é o 'médium' social em que se articulam e defrontam agentes coletivos e se consubstanciam relações inter individuais". A linguagem, assim, funciona também como elemento de interação social e introdução da pessoa na própria realidade, sendo um lugar de conflito, pois o confronto ideológico se dá na linguagem, e se torna inviável, estudar tais conflitos ou ideologias fora da sociedade sendo que os processos que a constituem são históricosociais. $O$ estudo da análise do discurso não pode estar desvinculado das condições de produção sociais, e as ideologias predominantes.

A análise do discurso está bastante marcada pela perspectiva teórica francesa, cuja vertente defendida por Michel Pêcheux (1997) propõe uma reflexão entre a linguística, o marxismo e a psicanálise. Por fim, vale lembrar que a análise do discurso nasce com base na interdisciplinaridade, pois ela vinha se mostrando como preocupação não somente para os linguistas, mas também a historiadores e alguns psicólogos.

Napoleão incute ao termo ideologia uma carga semântica negativa. Marx e Engels também vão significar o termo ideologia com cargas negativas, em que condenavam a maneira abstrata dos filósofos alemães, que, absortos em suas ideologias, não faziam as ligações entre a filosofia e as realidades vividas na Alemanha. Eles identificavam ideologia no interstício entre os processos de como se produziam as 
ideias, e as reais condições sociais e históricas que efetivamente as produziam (BRANDÃO, 1996).

Marx e Engels, citados por Brandão (1996), entendiam que a produção de ideias, concepções, e a construção da consciência partem diretamente do mundo material, e do comércio material dos homens, incluindo a força de trabalho. Contudo, segundo Marx e Engels, o que as ideologias faziam era colocar as coisas de cabeça para baixo, representando o desvio de percurso em que se parte primeiro das ideias para depois se chegar à realidade. Chaui (1995) destaca que a partir dessa leitura de ideologia de cabeça para baixo em Marx, se entende que ideologia para este autor é um:

sistema ordenado das ideias ou representações e das normas e regras como algo separado e independente das condições materiais, visto que seus produtores - os teóricos, os ideólogos, os intelectuais - não estão diretamente vinculados à produção material das condições de existência. E, sem perceber, exprimem essa desvinculação ou separação através de suas ideias (p. 65).

Essa leitura separatista entre o trabalho intelectual e material, de certa forma atribuía uma autonomia ao trabalho intelectual, ou às ideias, que ao prevalecer sobre o trabalho material passam a ser a expressão do que pensa a classe dominante. Segundo Marx e Engels (1965), o pensamento dominante, que efetivamente é o da classe dominante, é como se fosse uma força espiritual que regula a vida em sociedade. Assim dominam e regulamentam a produção e a distribuição de ideias que são da classe dominante sobre aqueles menos favorecidos em termos de poder de expressão, de exercício de linguagens no contexto social.

Chaui (1995) constata, a partir dessa linha de raciocínio, que a concepção marxista de ideologia, pode ser caracterizada como um instrumento de dominação de classe, em que a classe dominante faz com que suas ideias sejam ideias de todos. Para que seja possível criar na consciência dos sujeitos essa visão ilusória, construída pela classe dominante, foi criado um sistema lógico e coerente de representações, normas e regras, que direcionam, indicam e prescrevem como os membros da sociedade devem pensar, o que pensar e como pensar, o que deve ser valorizado, como se sentir, o que sentir. A partir das teorias do discurso fica mais fácil percebermos que como são propaladas, disseminadas; ou seja, através das narrativas históricas, dos discursos dominantes.

Em Marx a concepção de ideologia, por vezes, pode parecer estar reduzida a "uma simples categoria filosófica de ilusão ou mascaramento da realidade social" (BRANDÃO, p. 21, 1996). Porém, isso emana do fato de Marx tomar como ponto de partida a crítica ao sistema capitalista, e uma ideia de desmascaramento dessa ideologia burguesa. Assim, podemos ver que de fato a ideologia especifica da classe dominante é aquela que é frequente e reiteradamente produzida e reproduzida pelas estruturas e sistemas de poder. $\mathrm{O}$ que a análise do discurso, além de muitos outros enfoques de outros autores, nos ajuda a compreender e a fazer é uma leitura que mais se aproxime dos meandros dessa dominação e, portanto, da realidade possível de ser compreendida. Ou seja, com a análise do discurso buscamos compreender e elucidar quais os atravessamentos e as reais ideias embutidas nas narrativas dominantes de forma, digamos camuflada, nos discursos estabelecidos em sociedade pela classe 
dominante. Afinal, é o discurso uma das instâncias em que é possível ver a materialidade ideológica.

\section{CONSIDERAÇÕES FINAIS}

Dentre as reflexões que emergiram com nossas leituras e discussões, destacamos o fato de que não apenas a leitura, mas especificamente a prática da escrita é que potencializa a sua aprendizagem. Da mesma forma, vale destacar que a aprendizagem da escrita, assim como todas as outras, pressupõe o envolvimento da pessoa como um todo, com todos os sentidos. Nessa abordagem, portanto, procuramos não separar o viver do aprender (MATURANA, 2002), destacando a complexidade deste processo.

Nessa mesma direção, podemos trazer, ainda, algumas questões ligadas à ideia de experiência. Segundo Larrosa (2011) a questão da experiência tem muitas possibilidades no campo educativo. $O$ autor concebe experiência como: isso que me passa, ou seja, supõe um acontecimento, o passar de algo que não é a pessoa em si, algo que não depende dela, não sendo uma projeção de si mesma, resultado de suas palavras, representações, sentimentos e assim não depende do seu saber, nem de seu poder, nem de sua vontade. Para ele, então, não há experiência sem a aparição de alguém, ou de algo, ou de um isso, ou de um acontecimento exterior à pessoa, estranho e fora dela mesma, ainda que o lugar da experiência seja o individuo em si. É nas palavras, sentimentos, ideias, representações que se dá a experiência. O sujeito da experiência se exterioriza em relação ao acontecimento, com o qual se altera.

Se a experiência é isso que nos passa, que nos acontece, podemos dizer que o sujeito da experiência é como um território da experiência, como uma experiência de sensibilidade em que algo passa e que isso que passa e ao passar deixa vestígio, marca, rastro ou ferida (LARROSA, 2011).

Um exemplo, também utilizado pelo autor, seria a leitura de um texto, na qual duas pessoas podem ler o mesmo texto, mas a experiência que cada uma terá não será a mesma, pois a experiência é singular e mesmo que a mesma pessoa vá ler o mesmo texto por duas vezes, em cada uma delas a experiência será diferente. Assim, do ponto de vista da experiência, a leitura, e pensamos que também a escrita, pode ajudar a pessoa a dizer o que ainda não pode, ou não quer dizer. Em outras palavras, pode ajudar a formar ou a transformar a própria linguagem, transformando também a pessoa de maneira congruente.

Ao destacarmos que o mesmo acontece com a escrita, com o que nos passa com essa escrita, entendemos que há uma relação direta entre a escrita e a própria subjetividade, pois não se pode desenvolver uma escrita como se fora um caminho só de ida, onde não haveria reflexão, transformação. A experiência do escrever não apenas transforma o escritor, mas também transforma a escrita. Ou seja, tendemos a compreender a escrita como experiência que ocorre, que passa com aquele que escreve e esta envolve, sempre, todos os processos de reflexões, assim depois de escrever algo, este escritor não será mais o mesmo. Nós enquanto lemos e praticamos a escrita estamos em constante aprendizagem e transformação, nos subjetivando e transformando nossa própria linguagem, assim como nós mesmos em congruência com o todo.

A experiência soa a finitude. Isto é, há um tempo e a um espaço particular, limitado, contingente, finito. Soa também a corpo, isto é, a sensibilidade, a tato e a pele, a voz e a ouvido, a olhar, a sabor e a 
odor, a prazer e a sofrimento, a carícia e a ferida, a mortalidade. $\mathrm{E}$ soa, sobretudo, a vida, a uma vida que não é outra coisa que seu mesmo viver, a uma vida que não tem outra essência que a sua própria existência finita, corporal de carne e osso (LARROSA, 2011, p.25).

Conclusões parciais de nosso estudo apontam para uma espécie de crise da escrita enquanto exercício prazeroso para a maioria das pessoas, da qual as professoras em formação não estão isentas. Compreendemos isso considerando que as práticas de escrita mais valorizadas e potencializadas em nossa sociedade tem se restringido ao cumprimento de normas da convivência profissional e ou intelectual, e não da convivência humana. As escritas mais ligadas ao conviver consigo mesmo, com o corpo e com as pessoas de relações mais próximas, hoje, considerando especialmente as novas tecnologias são limitadas a poucas palavras que trocamos sem muito cuidado através da web e, por isso mesmo, na maioria das vezes não temos nem tempo nem condições de nos percebermos vivendo uma experiência de conhecer, de auto-conhecer-se e de transformar-se.

Por fim, levando em consideração as nossas práticas de escrita e as reflexões que o estudo nos permitiu realizar, pensamos que o menosprezo às práticas de escrita prazerosa produz uma discrepância com relação às possibilidades de aprendizagem que temos como seres humanos. Isto se confirma pelo fato de que aquilo que aprendemos e como aprendemos com as práticas de escrita não é possível que se realize com e/ou nas práticas de outras linguagens.

\section{REFERÊNCIAS}

BRANDÃO, Helena H. Nagamine. Introdução à análise do discurso. 5. ed. Campinas: Ed. da UNICAMP, 1996.

CHAUÍ, Marilena de Souza. O que é ideologia. 39. ed. São Paulo: Brasiliense, 1995.

LARROSA, Jorge. Experiência e alteridade em Educação. Revista Reflexão e Ação, Santa Cruz do Sul, v.19, n. 2, jul./dez., 2011.

MATURANA, Humberto R. Cognição, ciência e vida cotidiana. Belo Horizonte: Ed. da UFMG, 2001.

MATURANA, Humberto R.; VARELA, Francisco J. De máquinas e seres vivos: autopoiese: a organização do vivo. 3. ed. Porto Alegre: Artes Médicas, 1997.

MATURANA, Humberto R.; GARCIA, Francisco Varela. A árvore do conhecimento: as bases biológicas do entendimento humano. Campinas: Editorial Psy, 1995.

SENNETT, Richard. O Artífice. Rio de Janeiro: Record, 2009.

PECHEUX, Michel. O discurso. Estrutura ou Acontecimento. Campinas: Pontes, 1997. 